\title{
The effect of composition of mantle ultra-potassic fluids/melts on diamond formation processes
}

\author{
Yuri N. Palyanov, Alexander G. Sokol \\ Institute of Geology and Mineralogy SB RAS, Novosibirsk, Russian Federation
}

Analysis of micro-inclusions in mantle-derived and metamorphic diamonds shows that, to a first approximation, the composition of diamond crystallization medium can be considered as ultrapotassic fluids or melts with different ratio of carbonates, silicates, chlorides and water (Hwang et al., 2005; Klein-BenDavid et al., 2007). Experimental modeling of natural diamond-forming process is performed at high P-T parameters in the $\mathrm{K}_{2} \mathrm{CO}_{3}-\mathrm{H}_{2} \mathrm{O}$ $\mathrm{C}, \mathrm{K}_{2} \mathrm{CO}_{3}-\mathrm{KCl}-\mathrm{C}$ and $\mathrm{K}_{2} \mathrm{CO}_{3}-\mathrm{Mg}_{2} \mathrm{SiO}_{4}-\mathrm{C}, \mathrm{Mg}_{2} \mathrm{SiO}_{4}-$ $\mathrm{H}_{2} \mathrm{O}-\mathrm{C}$ subsystems (Palyanov et al., 2007, Sokol, Palyanov, 2008).

Experiments were carried out using a multi-anvil (8/6) high pressure apparatus of a "split-sphere" type. Details on the pressure and temperature calibration and accuracy of the measurements are given in ref. (Pal'yanov et al., 2002). The starting materials were a graphite disk (99.99\% purity), $\mathrm{K}_{2} \mathrm{CO}_{3}, \mathrm{KCl}$, synthetic forsterite of purity not less $99.9 \%$ and distilled water. The initial reagents and cubooctahedral diamond seed crystals were loaded into Pt capsules, which were sealed by arc welding.

In order to establish the influence of the crystallization environment composition on diamond nucleation and growth, most part of experiments were performed at fixed $\mathrm{P}, \mathrm{T}, \tau$ parameters $\left(\mathrm{P}=7.5 \mathrm{GPa}, \mathrm{T}=1600^{\circ} \mathrm{C}, \tau=15\right.$ h) and only the composition of melts and fluids was varied. The degree of the graphite-to-diamond conversion $(\alpha)$, which is a quantitative indicator of diamond-forming capability of the medium, was measured in each experiment. $\alpha=M_{D m} /\left(M_{D m}+M_{G r}\right) \cdot 100$, where $\mathrm{M}_{\mathrm{Dm}}$-mass of diamond, $\mathrm{M}_{\mathrm{Gr}}$-mass of graphite. Analysis of the experimental data permits establishing the following main regularities of diamond crystallization in the $\mathrm{K}_{2} \mathrm{CO}_{3}-\mathrm{KCl}-\mathrm{Mg}_{2} \mathrm{SiO}_{4}-\mathrm{H}_{2} \mathrm{O}-\mathrm{C}$ system.

In dry melts of the studied system diamond crystallizes mainly by the FG (film growth) mechanism, which occurs at the graphite-melt interface (Fig. 1,a). In this case the driving force for the diamond crystallization is the difference in solubility of graphite and diamond in the melt, at constant P-T parameters. For the dry $\mathrm{K}_{2} \mathrm{CO}_{3}$ melt it is established that for the given $\mathrm{P}, \mathrm{T}, \tau$ parameters the degree of the graphite-to-diamond conversion is $100 \%$. Addition of forsterite to the system and gradual increase in the $\mathrm{Mg}_{2} \mathrm{SiO}_{4} / \mathrm{K}_{2} \mathrm{CO}_{3}$ ratio result in a decrease in $\alpha$ and a change in diamond crystal morphology from cubo-octahedron to octahedron.

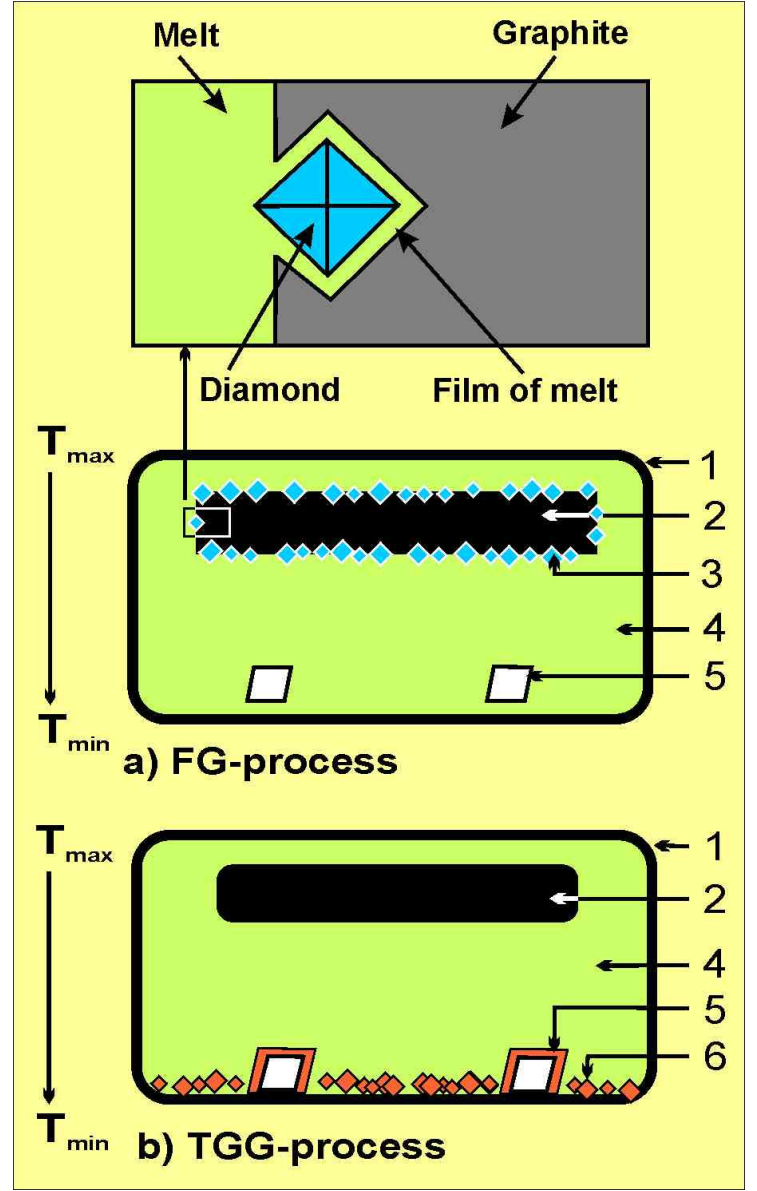

Fig. 1. Schemes of diamond crystallization in ultra-potassic fluid/melt-graphite systems. FG - Film Growth process; TGG - Temperature Gradient Growth process. 1-Pt capsule; 2graphite; 3-diamond obtained by FG - process; 4-melt; 5-seed crystal; 6-diamond obtained by TGG - process.

There is no difference in the intensity and character of diamond crystallization in the $\mathrm{K}_{2} \mathrm{CO}_{3}$ versus carbonatechloride melts, containing 25 and $50 \mathrm{wt} \% \mathrm{KCl}$, at $1600^{\circ} \mathrm{C}$, with $\alpha$ being equal to $100 \%$. When a chloridecarbonate melt $(80 \% \mathrm{KCl})$ was used, $\mathrm{KCl}$ crystallized at the bottom of the capsule and the melt with the components proportion of $\approx 1: 1$ was in contact with graphite. Experiments at 1550 and $1500^{\circ} \mathrm{C}$ show that the $\mathrm{K}_{2} \mathrm{CO}_{3}$ melt is more effective as diamond-forming medium than the carbonate-chloride melt. Diamonds crystallized in the $\mathrm{K}_{2} \mathrm{CO}_{3}-\mathrm{KCl}$ melt have cubooctahedral morphology (Fig. 2). 


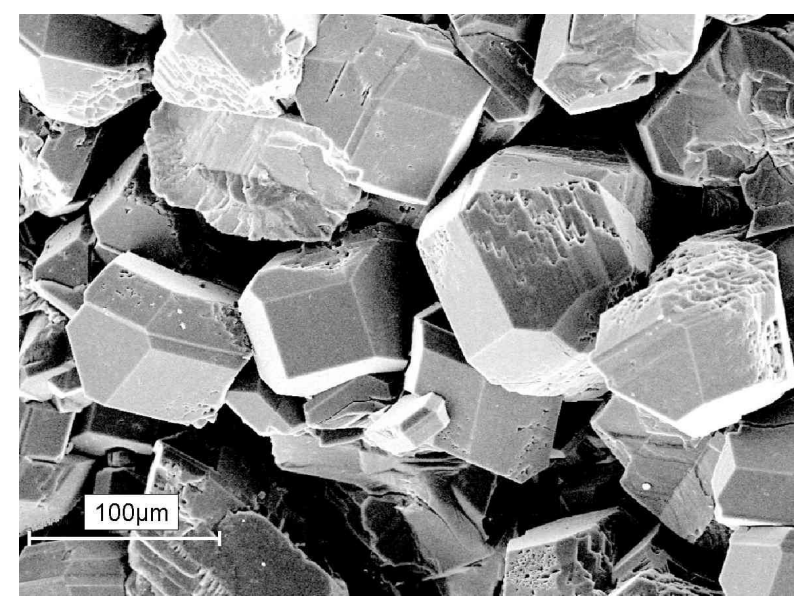

Fig. 2. SEM of cubo-octahedral diamonds synthesized in the $\mathrm{K}_{2} \mathrm{CO}_{3}-\mathrm{KCl}-\mathrm{C}$ system

Addition of $\mathrm{H}_{2} \mathrm{O}$ leads to a change of diamond crystallization mechanism from $\mathrm{FG}$ to $\mathrm{TGG}$ (temperature gradient growth). In this case diamond crystallization is driven by the difference in solubility of carbon at different temperatures within the thermal gradient field (Fig. 1,b). Addition of water to the $\mathrm{K}_{2} \mathrm{CO}_{3}$ completely terminates $\mathrm{FG}$ mechanism $\left(\alpha_{\mathrm{FG}}=0\right)$
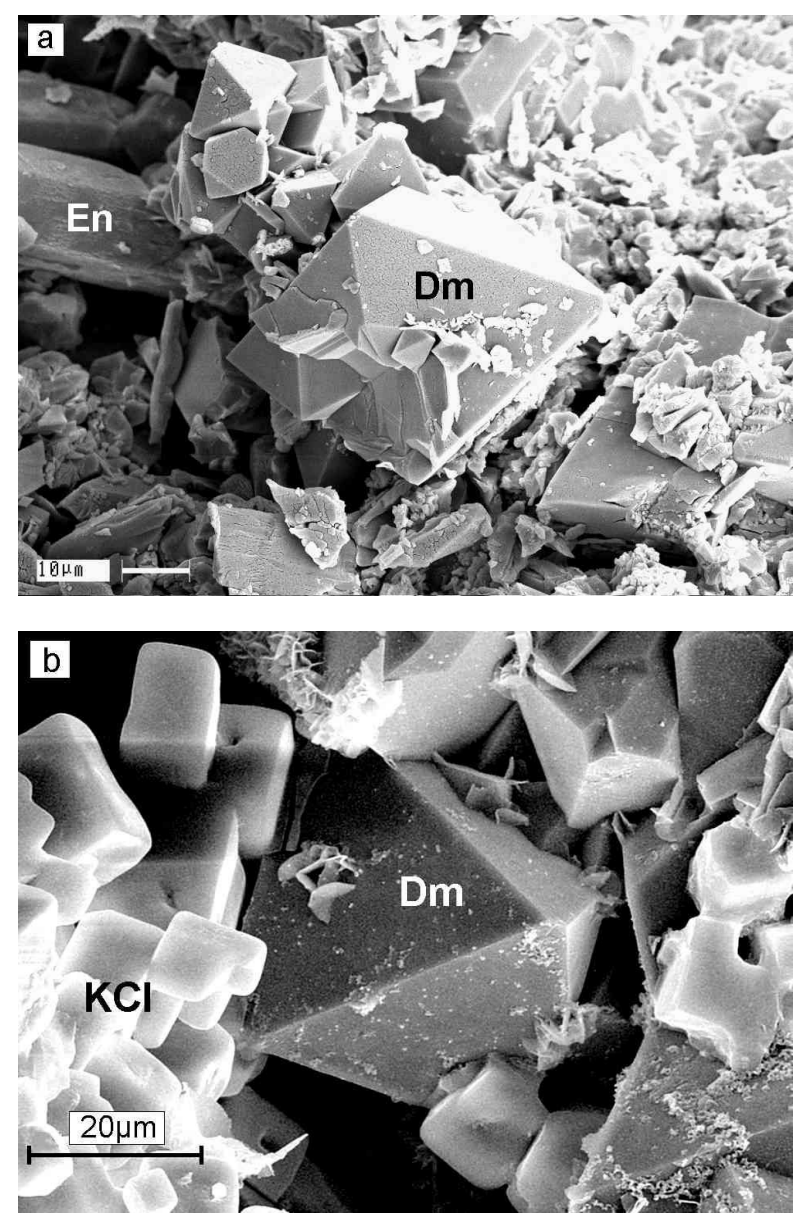

Fig. 3. Scanning electron micrographs of diamonds. a) octahedral diamonds synthesized in the in the $\mathrm{Mg}_{2} \mathrm{SiO}_{4}-\mathrm{H}_{2} \mathrm{O}-$ $\mathrm{C}$ system; b) octahedral diamonds synthesized in the $\mathrm{KCl}$ $\mathrm{H}_{2} \mathrm{O}-\mathrm{C}$ system. leaving only TGG acting, with $\alpha=\alpha_{\mathrm{TGG}}$ being very low $(6 \%)$ at $19 \mathrm{wt} \% \mathrm{H}_{2} \mathrm{O}$. Further increase in $\mathrm{H}_{2} \mathrm{O}$ content results in an abrupt increase in $\alpha$. In all watercontaining subsystems (carbonate-water, chloridewater, silicate-water) with an increase in $\mathrm{H}_{2} \mathrm{O}$ content, the intensity of diamond-forming process increases, with corresponding increase in $\alpha$. Depending on the $\mathrm{H}_{2} \mathrm{O}$ content the crystallization medium is either a water-containing melt (silicate, carbonate, chloride) or a $\mathrm{H}_{2} \mathrm{O}-\mathrm{CO}_{2}$ fluid containing dissolved silicates, carbonates or chlorides. An increase in $\mathrm{H}_{2} \mathrm{O}$ content in these media results in increase in $\alpha_{\mathrm{TGG}}$ from almost zero to $100 \%$. Most favorable conditions for diamond formation occur in the water-rich fluid phase, containing small amount of carbonate, silicate or chloride. Morphology of diamond crystals produced in the water-containing systems is shown in Fig. 3.

The results of experiments on diamond crystallization in the $\mathrm{K}_{2} \mathrm{CO}_{3}-\mathrm{KCl}-\mathrm{Mg}_{2} \mathrm{SiO}_{4}-\mathrm{H}_{2} \mathrm{O}-\mathrm{C}$ at $1600^{\circ} \mathrm{C}$ are summarized in Fig. 4. It should be noted that as the water content increases, first, heterogeneous nucleation and then homogeneous nucleation of diamond is established.

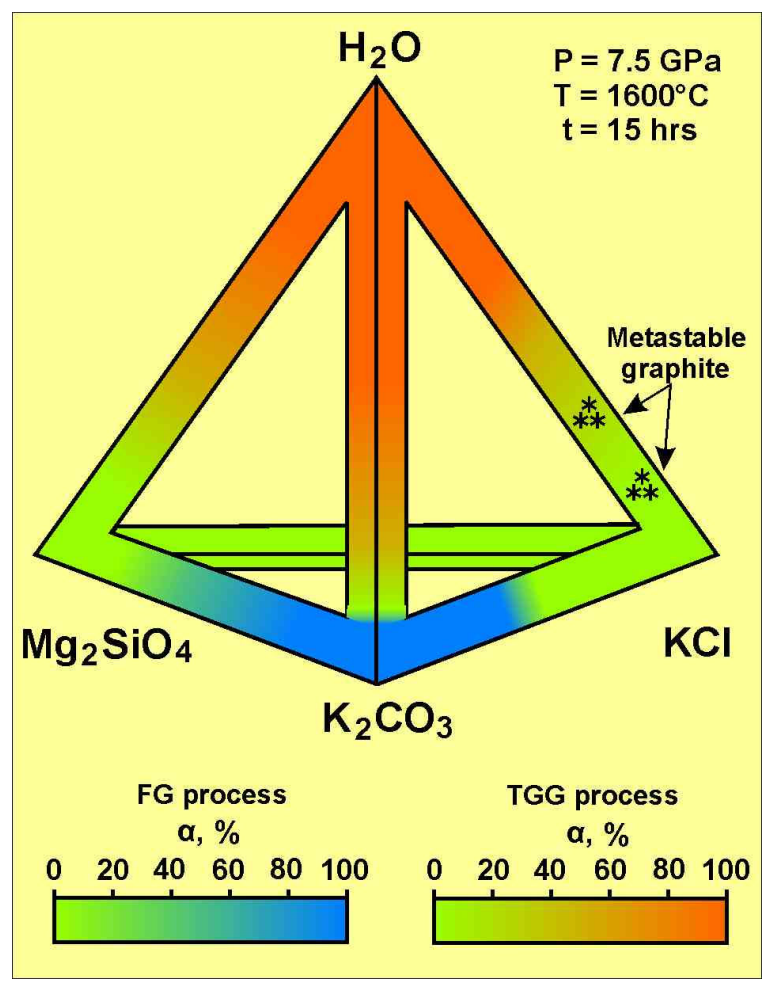

Fig. 4. Generalized diagram of the degree of graphite-todiamond conversion $(\alpha)$ in the $\mathrm{Mg}_{2} \mathrm{SiO}_{4}-\mathrm{K}_{2} \mathrm{CO}_{3}-\mathrm{KCl}-\mathrm{H}_{2} \mathrm{O}-\mathrm{C}$ system for FG (Film Growth - dark blue) and TGG (Temperature Gradient Growth - orange) processes. $\alpha=M_{D m} /\left(M_{D m}+M_{G r}\right) 100$, where $M_{D m}$ is the mass of obtained diamond and $\mathrm{M}_{\mathrm{Gr}}$ is the mass of residual graphite.

With equal $\mathrm{H}_{2} \mathrm{O}$ content and at constant $\mathrm{P}, \mathrm{T}$ and $\tau$ parameters the intensity of the diamond-forming fluids follows the sequence $\mathrm{K}_{2} \mathrm{CO}_{3}+\mathrm{H}_{2} \mathrm{O}>\mathrm{Mg}_{2} \mathrm{SiO}_{4}+\mathrm{H}_{2} \mathrm{O}>$ $\mathrm{KCl}+\mathrm{H}_{2} \mathrm{O}$. At $1600^{\circ} \mathrm{C}$ and $7.5 \mathrm{GPa}$ metastable graphite was found only in the $\mathrm{KCl}-\mathrm{H}_{2} \mathrm{O}-\mathrm{C}$ subsystem at 
relatively low contents of $\mathrm{H}_{2} \mathrm{O}$, namely 17 и $32 \mathrm{wt} \%$. On the example of the $\mathrm{K}_{2} \mathrm{CO}_{3}-\mathrm{KCl}-\mathrm{H}_{2} \mathrm{O}-\mathrm{C}$ system, it was shown that a decrease in temperature to $1500^{\circ} \mathrm{C}$ resulted in a decrease in the rate of diamond formation, but the general trend of the behavior of $\alpha$ as a function of the composition remained the same. At $7.5 \mathrm{GPa}$, a decrease in temperature leads to the appearance of metastable graphite in all subsystems. At constant temperature, the intensity of formation of metastable graphite changes substantially depending on the composition of crystallization medium in the succession: $\mathrm{KCl}+\mathrm{H}_{2} \mathrm{O}>\mathrm{K}_{2} \mathrm{CO}_{3}+\mathrm{H}_{2} \mathrm{O}>\mathrm{K}_{2} \mathrm{CO}_{3}+$ $\mathrm{KCl}>\mathrm{H}_{2} \mathrm{O}$. An increase in $\mathrm{H}_{2} \mathrm{O}$ content also results in a regular change in formation of carbon phases: crystallization of metastable graphite $\rightarrow$ joint crystallization of metastable graphite and diamond $\rightarrow$ crystallization of diamond. At low $\mathrm{H}_{2} \mathrm{O}$ concentrations only diamond growth on seed crystals is found. Diamond morphology is sensitive to changes in composition of crystallization medium. In all watercontaining systems diamond crystallizes exclusively in the form of octahedra. In dry melts of $\mathrm{K}_{2} \mathrm{CO}_{3}$, and $\mathrm{K}_{2} \mathrm{CO}_{3}+\mathrm{KCl}$ formation of cubo-octahedral diamonds is possible.

Summarizing, experimental studies on diamond crystallization in media, whose compositions correspond to mantle fluids/melts show that at constant $\mathrm{P}, \mathrm{T}$ and $\tau$ parameters the composition of the crystallization medium governs the mechanism of diamond crystallization, the degree of the graphite-todiamond conversion, diamond morphology and crystallization of metastable graphite.

The established sequences in crystallization of diamond and metastable graphite in the $\mathrm{K}_{2} \mathrm{CO}_{3}-\mathrm{KCl}$ $\mathrm{Mg}_{2} \mathrm{SiO}_{4}-\mathrm{H}_{2} \mathrm{O}-\mathrm{C}$ system, have been used to: $(i)$ model the composition of the mantle ultra-potassic fluid/melt; and (ii) prove the drastic changes in the intensity of diamond formation, depending on the composition of crystallization medium and temperature, which implies a considerable change in carbon solubility. As applied to natural diamond formation processes, the FG mechanism should act similarly to the experiments, being restricted by the conditions of existence of dry melt and graphite as the source of carbon. The TGG mechanism observed in experiments can not occur in nature, because such temperature gradients are impossible. However, it is possible that similar TGG may occur, in which the driving force of diamond crystallization is a change of supersaturation caused by temperature drop, change of fluid composition, and/or redox reactions. It is unlikely that, in the mantle and with UHP metamorphic processes, temperature could drastically change and, moreover, that temperature gradients could be great enough to provide diamond nucleation. The results of the present study show that the driving force for precipitating elemental carbon could be a change in concentrations of main components of carbonate-chloride-silicate-water medium. The change in the mechanisms of diamond crystallization and strong dependence of the processes of diamond formation on composition, as determined by the present study, suggest that the evolution of the fluid composition is the main important factor responsible for spontaneous diamond nucleation at constant pressure and temperature in the open system.

The change of fluid composition (e.g., enrichment in carbonates or chlorides) might cause joint crystallization of diamond and metastable graphite, leading to the formation of diamonds with graphite inclusions and graphite-coated diamonds. Some morphological features of diamonds also could be due to changes in the composition of the crystallization medium. For example, the evolution of composition from carbonate/chloride melt to aqueous fluid could change the stable growth form of diamond from cubooctahedral to octahedral, with the formation of morphology regeneration.

Finally, the results of our experimental study suggest that changes in the crystallization medium composition, even at constant P-T parameters, are able to initiate nucleation and growth of diamond, diamond dissolution, as well as formation of metastable graphite in the mantle and UHP metamorphic processes.

This work was supported by the Russian Foundation for Basic Research (grant No.06-05-64576).

\section{References}

Hwang, S-L., Shen, P., Chu, H-T., Yui, T-F., Liou, J.G., Sobolev, N.V., Shatsky, V.S., 2005. Crust-derived potassic fluid in metamorphic microdiamond. Earth Planet. Sci. Lett., 231, 295-306.

Klein-BenDavid, O., Izraeli, E.S., Hauri, E., Navon, O., 2007. Fluid inclusions in diamonds from the Diavik mine, Canada and the evolution of diamond-forming fluids. Geochim. Cosmochim. Acta 71, 723-744.

Palyanov, Yu.N., Shatsky, V.S., Sobolev, N.V., Sokol, A.G., 2007. The role of mantle ultrapotassic fluids in diamond formation. Proc. Nat. Acad. Sci., 104, 91229127.

Pal'yanov, Yu.N., Sokol, A.G., Borzdov, Yu.M., Khokhryakov, A.F., 2002. Fluid-bearing alkaline carbonate melts as the medium for the formation of diamond in the Earth's mantle: an experimental study. Lithos, 60, 145-159.

Sokol, A.G., Palyanov, Y.N., 2008. Diamond formation in the system $\mathrm{MgO}-\mathrm{SiO}_{2}-\mathrm{H}_{2} \mathrm{O}-\mathrm{C}$ at $7.5 \mathrm{GPa}$ and $1600^{\circ} \mathrm{C}$. Contrib. Mineral. Petrol., 155, 33-34. 